\title{
Effect of implementation of Integrated Management of Neonatal and Childhood Illness (IMNCI) programme on neonatal and infant mortality: cluster randomised controlled trial
}

\author{
(c) $\frac{(1)(8)}{\mathrm{gy}}$ MPEN ACCESS
}

\author{
Nita Bhandari director ${ }^{1}$, Sarmila Mazumder research coordinator ${ }^{1}$, Sunita Taneja research \\ coordinator ${ }^{1}$, Halvor Sommerfelt professor ${ }^{2}$, Tor A Strand professor ${ }^{2}$, on behalf of the IMNCI \\ Evaluation Study Group
}

${ }^{1}$ Centre for Health Research and Development, Society for Applied Studies, 45, Kalu Sarai, New Delhi-110016, India; ${ }^{2}$ Centre for International Health, University of Bergen and Norwegian Institute of Public Health, Norway

\begin{abstract}
Objective To evaluate the Indian Integrated Management of Neonatal and Childhood Illness (IMNCI) programme, which integrates improved treatment of illness for children with home visits for newborn care, to inform its scale-up.

Design Cluster randomised trial.

Setting 18 clusters (population 1.1 million) in Haryana, India.

Participants 29667 births in intervention clusters and 30813 in control clusters.

Intervention Community health workers were trained to conduct postnatal home visits and women's group meetings; physicians, nurses, and community health workers were trained to treat or refer sick newborns and children; supply of drugs and supervision were strengthened.

Main outcome measures Neonatal and infant mortality; newborn care practices.

Results The infant mortality rate (adjusted hazard ratio $0.85,95 \%$ confidence interval 0.77 to 0.94 ) and the neonatal mortality rate beyond the first 24 hours (adjusted hazard ratio $0.86,0.79$ to 0.95 ) were significantly lower in the intervention clusters than in control clusters. The adjusted hazard ratio for neonatal mortality rate was 0.91 ( 0.80 to 1.03). A significant interaction was found between the place of birth and the effect of the intervention for all mortality outcomes except post-neonatal mortality rate. The neonatal mortality rate was significantly lower in the intervention clusters in the subgroup born at home (adjusted hazard ratio $0.80,0.68$ to 0.93 ) but not in the subgroup born in a health facility $(1.06,0.91$ to1.23) ( $P$ value for interaction=0.001). Optimal newborn care practices were significantly more common in the intervention clusters.
\end{abstract}

Conclusions Implementation of the $\mathrm{IMNCI}$ resulted in substantial improvement in infant survival and in neonatal survival in those born at home. The IMNCI should be a part of India's strategy to achieve the millennium development goal on child survival.

Trial registration Clinical trials NCT00474981; ICMR Clinical Trial Registry CTRI/2009/091/000715.

\section{Introduction}

Approximately $28 \%$ of all deaths of newborns and $23 \%$ of all infant deaths in the world occur in India. ${ }^{1}$ Many of these deaths could be prevented by greater access to and use of high quality healthcare in combination with improved newborn and infant care practices in families. ${ }^{2}$

India adapted the Integrated Management of Childhood Illness (IMCI) strategy, ${ }^{3}$ aiming to reduce its newborn and infant mortality burden and renamed the revised strategy Integrated Management of Neonatal and Childhood Illness (IMNCI). ${ }^{4}$ In addition to treatment of sick newborns and children, it incorporates home visits for early newborn care, which have been shown to reduce mortality among newborns in Gadchiroli, India. ${ }^{5}$ The home visits focus on improving newborn and infant care practices and care seeking for illness.

Implementation of IMNCI started in India in 2003. By June 2010, it had been implemented in 223 of India's 640 districts and more than 200000 workers had been trained. Evaluating the effect of this strategy was identified as a priority for research in the Lancet's newborn series, ${ }^{6}$ a priority shared by the Ministry of Health of India. The evaluation is also expected to provide insights for accelerating the scale-up of IMNCI, supporting 
efforts to achieve the millennium development goal on child survival.

This cluster randomised controlled trial, assessing the effectiveness of the strategy when delivered to a population of more than a million, was conducted in Haryana, India. This paper reports on the effect on newborn and infant mortality and on newborn care practices.

\section{Methods}

\section{Setting}

We carried out the trial in communities with a population of 1.1 million served by 18 primary health centres in the district of Faridabad, Haryana, India. Although contiguous, the 18 clusters are large and the way healthcare and worker responsibilities are organised within a primary health centre area makes the risk of contamination low. The population of each primary health centre ranged from 10694 to 72059 . About half the mothers had never been to school, and two thirds of the births took place at home. Previous studies in the same area showed that $35 \%$ of newborns are of low birth weight and $60 \%$ of sick children are taken for care to medically unqualified private practitioners. ${ }^{78}$

\section{Baseline survey}

We did a baseline survey in all 18 primary health centres (clusters) from June to October 2006 to ascertain information for randomisation. Trained study workers did a door to door survey. Study managers and coordinators provided oversight. We arranged the 18 clusters in alphabetical order and used Stata software to generate a "random" number between 0 and 1 for each cluster in the list. We then reordered the primary health centres on the basis of the random numbers (ascending order of random numbers). The clusters were visited in sequence according to this reordered list.

Information gathered was limited to characteristics needed for randomisation - that is, proportion of home births, proportion of mothers who had never been to school, population per cluster, and neonatal and infant mortality rates. After obtaining consent, we interviewed all women in a household in the reproductive age group to obtain their pregnancy history, which included the outcome of all pregnancies and, in the case of live births, the date of birth and the vital status of the child at the time of survey. For all infant deaths, we documented the date of death. Repeat visits were made to all households where families were not available.

\section{Randomisation}

Health workers who implement IMNCI are supervised by and report to primary health centres. We therefore used the catchment areas of the 18 primary health centres in the district as the clusters for this trial. We divided the clusters into three strata containing six clusters each according to their baseline neonatal mortality rate. An independent epidemiologist generated 10 stratified randomisation schemes to allocate the clusters to intervention or control groups. We excluded three of these schemes, which had large differences in neonatal mortality rate, proportion of home births, proportion of mothers who had never been to school, and population size. We selected one of the remaining seven allocation schemes by a computer generated random number.

\section{Intervention}

The intervention was designed according to the IMNCI guidelines defined by the Government of India. ${ }^{9-12}$ It was implemented from January 2007 to April 2010. It consisted of three activities (table $1 \Downarrow$ ).

\section{Training health workers to implement IMNCI}

All community health workers, auxiliary nurses, and physicians working in the nine intervention areas were trained in improving case management skills by using the Government of India's IMNCI training modules. . Anganwadi workers (village based child development and nutrition workers, 601 in number) and their supervisors, accredited social health activists (village based health workers, 488 in number), and auxiliary nurse midwives (128 in number) were trained with the eight day IMNCI Basic Health Worker Course. ${ }^{10}$ All 14 government sector physicians involved in child care were trained with the 11 day IMNCI Course for Physicians. ${ }^{11}$ The trainers subsequently visited trainees at their place of work to review their performance, overcome challenges to implementation, and support the use of skills learnt.

The 13 medically qualified private providers practising in the intervention areas were offered participation in a single session of six hours adapted from the IMNCI Course for Physicians. Private practitioners who were not medically qualified were also invited for orientation sessions that took place on two consecutive days for about three hours. Orientation sessions covered neonatal conditions requiring referral, pre-referral treatment, problems that can be managed at home, and components of essential newborn care. ${ }^{13} 14$ The orientation also included management of diarrhoea and pneumonia and appropriate complementary feeding practices in older children. Of a total of 973 non-qualified private providers practising in the intervention areas, 614 attended IMNCI orientation. Traditional birth attendants in the intervention areas were invited for a four hour orientation on clean delivery, cord care, and newborn care. ${ }^{12-14}$

\section{Strengthening the health system to implement IMNCl}

Consistent with the Government of India's policy, ${ }^{12}$ and in consultation with the district health authorities, three sets of activities were implemented. Firstly, supervision of community health workers and nurses was strengthened in the intervention clusters. Vacant supervisor positions (21 in number) were filled through temporary hiring. Supervisors were trained in IMNCI and supervision skills. ${ }^{10}{ }^{15}$ Secondly, task based incentives were expanded to include IMNCI activities. Community health workers routinely get incentives for promoting institutional births (100 rupees; $£ 1.27 ; € 1.52 ; \$ 2.00)$ and immunisation (100 rupees). In the intervention clusters, they received additional incentives for doing postnatal home visits ( 75 rupees), treating sick newborns and children (35 rupees), and running women's group meetings ( 35 rupees). Thirdly, drug depots were established in villages to ensure regular supply of IMNCI drugs to community health workers for treating newborns and older children.

\section{Implementing IMNCI}

Health workers in intervention clusters started implementing the following IMNCI activities from January 2008 (table $1 \Downarrow$ ). Community health workers (Anganwadi workers) made postnatal home visits on days 1,3 , and 7 to promote early and exclusive breast feeding, delaying bathing, keeping the baby warm, cord care, and care seeking for illness. They assessed newborns for signs of illness at each visit and treated or referred them. ${ }^{10}$ They additionally visited low birthweight infants on 
days 14, 21, and 28. Community health workers (accredited social health activists), nurses, and physicians treated sick newborns and older children according to IMNCI guidelines. Community health workers (accredited social health activists) ran women's group meetings in every village every three months to raise awareness about newborn care practices.

Community health workers, nurses, and physicians continued to provide their routine services in both intervention and control areas (table $1 \Downarrow$ ).

\section{Outcomes and their ascertainment}

The primary outcomes were neonatal mortality (deaths between birth and day 28 of life), mortality beyond the first 24 hours of birth (deaths between day 2 and day 28 of life), and infant mortality (deaths between birth and day 365 of life). Outcomes were ascertained in a cohort of infants born to women identified through pregnancy surveillance. The secondary outcomes included newborn care practices and process of delivery of the intervention. In this paper, we report results on all primary outcomes and on newborn care practices. We also report on two additional mortality outcomes, perinatal mortality (stillbirths and deaths between birth and day 7 of life $)^{16}$ and post-neonatal mortality (deaths between day 29 and day 365 of life), for comparison with previous studies. Results on the process of intervention delivery will be reported separately.

We allocated all households in the intervention and control areas to one of the 110 study field workers who were not involved with IMNCI implementation. The workers visited the allocated households every month to identify new pregnancies and inquire about the outcome of previously identified pregnancies. All households with live births were visited on day 29 and at ages $3,6,9$, and 12 months to document the vital status of the infant. The surveillance team comprised workers who resided in or near to the areas allocated to them. The surveillance team was not told the intervention status of the community they were visiting. The follow-up procedures were identical in all the clusters. A separate team of research assistants interviewed a randomly selected sub-sample of mothers at 29 days to ascertain newborn care practices and exposure to the intervention.

An independent team visited each household with a death as soon as possible to do a verbal autopsy, a technique for ascertaining the probable cause of death used in settings lacking vital registration and medical certification of deaths. An interview was carried out with family members of the deceased by using a structured questionnaire to elicit signs and symptoms and other pertinent information, which was used to assign a probable cause of death. ${ }^{17}$

\section{Sample size estimates}

Using data from the baseline survey, we estimated that we would need 40500 infants in intervention and control clusters to detect a $20 \%$ reduction in neonatal mortality rate. We revised these estimates upwards after one year of the study on the basis of two factors. Firstly, although the mortality was observed to be higher than in the baseline survey, the variation across clusters was greater. Secondly, we added neonatal mortality after 1 day (day 2 to 28 day mortality) as a primary outcome because we found that more than $40 \%$ of deaths were occurring in the first 24 hours of life (higher than expected), ${ }^{18}$ on which the intervention was unlikely to have an effect. The required sample size was based on the following assumptions: neonatal mortality rate in study area 40/1000, neonatal mortality rate after 1 day $24 / 1000$, and infant mortality rate 60/1000; coefficient of variation between clusters $(\mathrm{k})$ about $0.11 ; 80 \%$ power and $5 \%$ significant level. As the number of clusters available in the study district was fixed (nine per group), we calculated the number of live births per cluster needed to detect a difference between the intervention and control groups of $20 \%$ in neonatal mortality rate, $20 \%$ in neonatal mortality rate after 1 day, and $18 \%$ in infant mortality rate. ${ }^{78}$ This worked out to be 3330 births per cluster. Assuming an attrition of $10 \%, 3700$ births per cluster would have to be recruited, giving a total of approximately 66 600 births. As the attrition rates were much lower than anticipated (about 2\%), the Data Safety Monitoring Board considered that the required sample size had been completed in March 2010 after recruitment of 60702 live births.

\section{Statistical analysis}

We analysed the data according to intention to treat by using Stata software version 10.0. We included births between 1 January 2008 and 31 March 2010 from pregnancies identified through the surveillance. As the follow-up visits were stopped six weeks after 31 March 2010, enrolled infants had a variable follow-up ranging from one to 12 months. We calculated days of follow-up for each infant by subtracting the date of birth from the date of last follow-up visit or the date of death.

We compared time until death between the intervention and control clusters by using a Cox proportional hazard model. We used the shared frailty option to account for cluster randomisation (except for neonatal deaths beyond first 24 hours of birth and post-neonatal deaths, for which we adjusted for cluster design with robust standard errors as the shared frailty option failed). We adjusted the resulting hazard ratios for important cluster level and individual level differences by including these as covariates in the model. Potential cluster level confounders identified in the baseline survey were the distance between the primary health centre facility and the nearest point on the highway and the proportion of home births in the cluster. Individual level characteristics for which the results were adjusted were illiterate mother, toilet inside the house, schedule caste or tribe, possession of mobile phone, and possession of a below poverty line card by the family.

As we expected the intervention to have a greater benefit in infants born at home, we had made an a priori decision to do a subgroup analysis to examine the effect of the intervention in the population of infants born at home and those born in a health facility. We assessed whether place of birth (home or facility) modified the effect of the intervention by including tests of interaction in the Cox models. We analysed newborn care practices (secondary outcomes) by using logistic regression models adjusting for cluster randomisation and all the potential confounders listed above.

\section{Results}

Table $2 \Downarrow$ shows the characteristics of the intervention and control clusters; the top half of the table shows the characteristics obtained from the baseline survey done in 2006. Whereas the proportion of mothers who had never been to school and the population of the clusters were similarly distributed between intervention and control groups, the intervention clusters were further away from the highway $(15.3 \times 7.0 \mathrm{~km}, \mathrm{P}=0.045)$ and had a somewhat higher proportion of home births $(71.9 \% \mathrm{~V}$ $65.9 \%, \mathrm{P}=0.272$ ) than the control clusters. The bottom half of the table shows the characteristics of the families of recruited births. These were similar in the intervention and control groups, except that a higher proportion of families in the intervention group had a below poverty line card $(18.4 \%$ v $10.6 \%, \mathrm{P}=0.004)$ and fewer had a toilet in the house $(37.7 \% \mathrm{v} 46.0 \%, \mathrm{P}=0.168)$, 
suggesting a lower economic status, and the proportion of illiterate mothers was lower in the intervention group (37.8\% v $41.7 \%, \mathrm{P}=0.374)$.

During the outcome assessment period (January 2008 to March 2010), we registered a total of 77587 pregnancies, of which the outcomes were not known in 10239 (13.2\%). Of these, 9954 women were still pregnant when recruitment of live births in the trial was stopped; few pregnant women (285) had left the area or died. We recorded 5147 (6.6\%) miscarriages/abortions, $1499(1.9 \%)$ stillbirths, and 60702 (78.2\%) live births in the study area. According to plan, follow-up ended six weeks after recruitment was completed. Consequently, although almost all recruited live born infants were followed for the newborn period (97.8\%), only $75.4 \%$ were followed for six months and $52.6 \%$ until the end of infancy (figure $\Downarrow$ and web appendix).

\section{Exposure to components of intervention}

In the sub-sample of infants whose families were interviewed when they were aged 29 days, 5582 (90\%) of the 6204 caregivers in the intervention clusters reported being visited at home by a community health worker at least once in the first 10 days after the child's birth, $4557(73.5 \%)$ were visited at least twice, and $2642(42.6 \%)$ had the recommended three visits. An early visit in the first two days after birth was reported by $3514(56.6 \%)$ caregivers. Two thousand eight hundred and twenty eight (45.6\%) mothers in the intervention clusters reported having attended at least one women's group meeting in the previous three months. The proportion of neonates with severe illness who were taken to an appropriate healthcare provider (defined as a physician, nurse, auxiliary nurse midwife, accredited social health activist, or Anganwadi worker) was $542 / 1010(53.7 \%)$ in the intervention clusters and 432/1269 $(34.0 \%)$ in the control clusters.

\section{Effect of intervention on primary outcomes}

The infant mortality rate was significantly lower in the intervention clusters than in the control clusters (adjusted hazard ratio $0.85,95 \%$ confidence interval 0.77 to 0.94 ). The adjusted hazard ratio for neonatal mortality rate was 0.91 ( 0.80 to 1.03 ) in the intervention compared with the control clusters. However, neonatal mortality rate beyond the first 24 hours was significantly lower in the intervention clusters (adjusted hazard ratio $0.86,0.79$ to 0.95 ) (table $3 \Downarrow$ ).

We found a significant interaction between the place of birth and the effect of the intervention for all primary outcomes. The neonatal mortality rate was significantly lower in the intervention clusters in the subgroup born at home (adjusted hazard ratio $0.80,0.68$ to 0.93 ) but not in the subgroup born in a health facility (1.06, 0.91 to 1.23 ) (P value for interaction=0.001) (table $4 \Downarrow)$. Infant mortality (adjusted hazard ratio $0.77,0.69$ to 0.87 ) and neonatal mortality beyond the first 24 hours $(0.76,0.65$ to 0.90$)$ were also significantly lower in the intervention clusters than in the control clusters among home births but not among facility births (table $4 \Downarrow$ ).

\section{Effect of intervention on other mortality outcomes}

The perinatal and post-neonatal mortality rates were significantly lower in the intervention clusters (table $3 \Downarrow$ ). Whereas the effect of the intervention on perinatal mortality rate was seen only among home births, the intervention led to a reduction in post-neonatal mortality rate both among home births (adjusted hazard ratio $0.73,0.63$ to 0.84$)$ and among facility births $(0.81$, 0.69 to 0.96 ).

\section{Effect of intervention on newborn care practices}

Table $5 \Downarrow$ shows that caregivers in the intervention areas reported considerably higher levels of optimal newborn care practices than did mothers in the control areas. Almost $41 \%$ of the caregivers in the intervention clusters reported starting breast feeding within an hour of birth, compared with $11.2 \%$ in the control clusters (odds ratio 5.21, 4.33 to 6.28 ). The proportion of infants exclusively breast fed at 4 weeks of age in the IMNCI clusters was more than twice that in the control clusters $(77.6 \%$ v $37.3 \%$; odds ratio $6.32,5.29$ to 7.55 ). More caregivers in the intervention group $(84.5 \%)$ delayed bathing neonates for at least 24 hours than in the control group (46.2\%; odds ratio 6.35, 4.65 to 8.68 ), and more reported having complied with the recommended practice of applying nothing or only gentian violet on the umbilical cord than in the control clusters $(84.1 \% \mathrm{v}$ $39.5 \%$; odds ratio $8.20,6.43$ to 10.45 ). Two practices did not differ much between intervention and control areas: appropriate clothing of the infant on the first day of life, which was almost universally practised in both groups $(97.5 \%$ v $97.9 \%)$ and skin-to-skin contact on the first day of life, which was practised for only $1.7 \%$ of the newborns in the intervention clusters and $0 \%$ in the control clusters.

We found a significant interaction between the place of birth and effect of the intervention on several newborn care practices: breast feeding started within one hour, pre-lacteal feeds not given, exclusive breast feeding at 4 weeks of age, infant given the first bath 24 hours or more after birth, and nothing or only gentian violet paint applied on the infant's cord $(\mathrm{P}<0.001$ for all) (table $6 \Downarrow$ ). The recommended newborn practices were improved in the intervention group in home born as well as facility born babies, but the magnitude was higher in the home born subgroup (table $6 \Downarrow$ ).

\section{Discussion}

This is one of the largest trials evaluating complex child survival interventions and the first evaluating the Indian Integrated Management of Neonatal and Childhood Illness programme. The main finding of this study is that IMNCI, implemented according to the Indian government's plan, resulted in a significant reduction in infant deaths, neonatal deaths beyond 24 hours of life, and perinatal deaths. We did not find a significant reduction in neonatal mortality, largely because a significant interaction occurred between the intervention and place of birth. As hypothesised, neonatal mortality was significantly reduced in babies born at home born but not in those born in health facilities. Post-neonatal mortality was, however, reduced in both home born and facility born infants. The attribution of the observed effect to IMNCI is highly plausible given the randomised controlled trial design and the observed effect of the intervention on intermediate outcomes. The intervention group had a higher prevalence of optimal newborn care practices, including starting breast feeding within an hour of birth, not giving pre-lacteal feeds, exclusive breast feeding, delayed bathing, and applying nothing or gentian violet paint on the umbilical cord. Many of these practices have been shown to reduce morbidity and thereby neonatal and infant mortality. ${ }^{2}$ We also observed that the intervention increased timely seeking of healthcare from appropriate sources for sick newborns and infants, which could have resulted in reduced severity of illness and ultimately reduced mortality (details of results on effect on morbidity and care seeking will be published separately). 
The prevalence of stillbirths was significantly reduced in the intervention clusters, even though we did not expect IMNCI to have an effect on stillbirths. On the other hand, we did not see any effect of the intervention on neonatal deaths in the first 24 hours after birth. We believe that this could have resulted from a differential misclassification between stillbirths and day 1 deaths in intervention and control groups. Fewer neonatal deaths are likely to be misclassified as stillbirths when a newborn focused intervention such as IMNCI is implemented. This could have led to an apparent reduction in the number of stillbirths and a corresponding increase in the number of very early neonatal deaths in the intervention clusters. Such an unexpected reduction in the number of stillbirths has been reported in previous trials of newborn interventions (for example, the First Breath Study). ${ }^{16}$ The observed effect on perinatal mortality in our trial is not likely to have been affected by this differential misclassification, but it could have reduced the observed effect on neonatal and infant mortality, thus making the corresponding effectiveness figures underestimates of the true effects.

\section{Strengths and weaknesses of study}

Among the strengths of this study are the cluster randomised study design, independent and similar measurement of outcomes in intervention and control areas, large size of the study population, and delivery of the intervention by the district health system.

A few potential limitations of the trial should be noted. Firstly, the trial included only 18 clusters, even though the cluster size was very large. Only 18 primary health centres were available in the study district. Choosing a smaller unit of randomisation, such as a sub-centre that covers a fifth of the population of a primary health centre, would have given us a larger number of clusters and improved randomisation and statistical efficiency. However, this would have resulted in a high risk of contamination because health workers in a primary health centre share mechanisms for supervision, monitoring, and supply of drugs. Secondly, some important baseline differences between the intervention and control groups remained despite the randomisation; the intervention areas were less accessible, had a lower proportion of births in health facilities, and had families with lower economic status but higher literacy. We have adjusted for these differences in the analysis. Thirdly, not all the newborns and their families received the intervention. As we wanted to do a study relevant to the programme, in which the intervention was delivered by the district health system, and not an efficacy study in which the delivery of intervention is fully controlled by the research team, a less than optimal coverage by the intervention could not be prevented.

\section{Findings in context of similar trials}

Our study is different from other trials evaluating community based newborn care interventions and IMCI, ${ }^{20-27}$ because the former focused only on the newborn period and the latter did not include the first week of life. Our study evaluates a comprehensive strategy with a focus on newborns as well as infants and children, delivered within a district health system on a large scale.

Previous evaluations of community based newborn care interventions, with the exception of one study, ${ }^{21}$ showed $30-61 \%$ reductions in neonatal mortality. ${ }^{202-24}$ In our study, we observed a reduction in neonatal mortality only in babies born at home. The factors that may explain findings across studies include the proportion of home births in different settings, characteristics of the populations, and the way the intervention was actually delivered. Also, most of the previous studies were in smaller populations, had a highly resource intensive delivery of the intervention, and did not include interventions beyond the neonatal period. A recently published large effectiveness study conducted in Pakistan almost concurrently with our study showed that community interventions in the antenatal and neonatal period resulted in a $15 \%$ (95\% confidence interval $4 \%$ to $24 \%$ ) reduction in neonatal mortality. ${ }^{27}$ Our study evaluates the more comprehensive IMNCI strategy on an even larger scale.

The evaluations of IMCI in Bangladesh and Tanzania show a significant $13 \%$ reduction in child mortality in Tanzania but no significant effect in Bangladesh. ${ }^{25}{ }^{26}$ These two trials differed from our study, which found a $15 \%$ reduction in infant mortality, by not including interventions during the first week of life. Notably, in our trial post-neonatal mortality was reduced both in home born and facility born infants.

\section{Policy implications}

This study provides several lessons for implementers of child health programmes. Firstly, implementation of IMNCI, as envisioned in the government's strategic plan, ${ }^{12}$ is feasible in India at scale and results in improved infant survival. Furthermore, neonatal survival is improved substantially in those born at home. IMNCI thus has a particularly good effect in locations where a high proportion of births occur at home. In our study, implementation of IMNCI improved newborn care practices in both home born and facility born infants, but the effect was substantially greater in those born at home. In the control group, the prevalence of critical newborn care practices such as starting breast feeding early was low in facility born infants, similar to that in home born infants. We therefore believe that the overall effect on neonatal mortality could be enhanced by increasing the emphasis on essential newborn care, including promotion of optimal newborn care practices (as in IMNCI) in facilities during the initial hours and days after birth. Secondly, we believe that high quality training, ensuring adequate supervision, timely supplies, and task based incentives to community health workers, as provided in this study, was critical for the observed effect.

Thirdly, home visits during the first week after birth, a critical component of IMNCI, can be implemented with high coverage. More than half (56\%) of the newborns were visited during the first two days after birth, a time when a home visit has been shown to be most effective. ${ }^{28}$ We believe that the proportion of newborns who receive an early postnatal visit could be increased by including home visits during pregnancy in the design of the IMNCI programme. This would improve the rapport of community health workers with families and facilitate the achievement of early postnatal visits. Finally, we found that referral facilities that offer high quality care were not readily accessible to families of severely ill children. Again, the IMNCI programme does not include an emphasis on improved referral care for sick newborns and children and does not have specific interventions to link communities with referral facilities. The effect of IMNCI might be even greater than seen in this study if the proportion of early home visits, essential newborn care in health facilities, and access to quality referral care can be increased.

\section{Conclusions}

The findings of this study have major implications for India and other countries where neonatal and infant mortality are high, particularly in settings where most births occur at home. 
Comprehensive integrated strategies such as IMNCI are feasible to deliver and significantly affect infant mortality; neonatal mortality is substantially improved among those born at home. Implementation of such strategies at scale, in combination with improved quality of maternal and newborn care in health facilities, should be a major approach for achievement of millennium development goal 4.

We thank Harish Kumar and V K Anand for facilitation of the IMNCI training and providing feedback at different stages. We acknowledge the members of the Data Safety Monitoring Board: Simon Cousens (chair), Bert Pelto, and Siddarth Ramji. We thank Marzio Babille for his support in initiating the trial. We thank the government of Haryana and the civil surgeons of Faridabad and Palwal districts in position during the study for their cooperation, and the participating health and ICDS officers and workers of the Faridabad district. We acknowledge the cooperation extended by the population of the district who participated in the study. We are grateful for the core support provided to our organisation by the Department of Child and Adolescent Health and Development, World Health Organization (Geneva), and Centre for International Health, University of Bergen (Norway).

IMNCI Evaluation Study Group: Brinda Dube, Jasmine Kaur, R C Aggarwal, Divya Pandey, Vaibhaw Purohit, Amarnath Mehrotra.

Study Advisory Group: Jose Martines, Rajiv Bahl, Pavitra Mohan, Betty R Kirkwood, Henri Van Den Hombergh, M K Bhan (chair).

Contributors: All authors contributed substantially to the design and conduct of the study, its analysis, and the writing of the manuscript. SM, ST, Brinda Dube, and NB were responsible for the daily implementation of the study. Jose Martines, Rajiv Bahl, Pavitra Mohan, Betty Kirkwood, TAS, and HS provided technical inputs during all stages of the project and analysis. All authors approved the final manuscript. All authors had full access to all of the data in the study and take responsibility for the integrity of the data and accuracy of the data analysis and their presentation. NB is the guarantor.

Funding: The study was funded by the World Health Organization, Geneva (through an umbrella grant from USAID); the United Nations Children's Fund, New Delhi; and the GLOBVAC Program of the Research Council of Norway through grant No 183722. Individual scientists at WHO and Unicef contributed importantly to the planning, analysis, and reporting of this study. However, the central bodies of these agencies and the Research Council of Norway had no influence on how the data was collected, analysed, or presented. The corresponding author had full access to all data that were analysed and had final responsibility for the decision to submit the manuscript for publication.

Competing interests: All authors have completed the ICMJE uniform disclosure form at www.icmje.org/coi_disclosure.pdf (available on request from the corresponding author) and declare: no support from any organisation for the submitted work; no financial relationships with any organisations that might have an interest in the submitted work in the previous three years; no other relationships or activities that could appear to have influenced the submitted work.

Ethical approval: Ethics committees of the Society for Applied Studies (IRB00001359) and the WHO (Geneva) approved the study. Permissions were obtained from state and district authorities, community leaders, and women under surveillance. Informed consent was taken from women with a live birth, before the first interview.
Data sharing: Requests for data sharing to the corresponding author (CHRD@sas.org.in) will be considered on approval from the Study Advisory Group.

1 United Nations Children's Fund. Levels and trends in child mortality: report 2010. Estimates developed by the UN Inter-Agency Group for Child Mortality Estimation. Unicef, 2010.

2 Darmstadt GL, Bhutta ZA, Cousens SN, Adam T, de Bernis L, Walker N. Evidence-based, cost-effective interventions that matter: how many newborns can we save and at what cost? Lancet 2005;365:977-88.

3 World Health Organization. IMCl adaptation guide, version 5. WHO, 1998.

4 World Health Organization. Integrated management of neonatal and childhood illnesses. WHO, 2003.

5 Bang AT, Bang RA, Baitule SB, Reddy H, Deshmukh MD. Effect of home-based neonata care and management of sepsis on neonatal mortality: field trial in rural India. Lancet 1999;354:1955-61

6 Martines J, Paul VK, Bhutta ZA, Koblinsky M, Soucat A, Walker N, et al. Neonatal survival: a call for action. Lancet 2005;365:1189-97.

7 Bhandari N, Bahl R, Mazumder S, Martines J, Black RE, Bhan MK. Effect of community-based promotion of exclusive breastfeeding on diarrhoeal illness and growth: a cluster randomised controlled trial. Lancet 2003;361:1418-23.

8 Bhandari N, Mazumder S, Taneja S, Dube B, Agarwal RC, Mahalanabis D, et al. Effectiveness of zinc supplementation plus oral rehydration salts compared with oral rehydration salts alone as a treatment for acute diarrhoea in a primary care setting: a cluster randomised trial. Pediatrics 2008;121:e1279-85.

9 Government of India, Ministry of Health and Family Welfare. Integrated management of neonatal and childhood illness: introduction, module 1. Government of India, 2003.

10 Government of India, Ministry of Health and Family Welfare. IMNCI training module for workers. Government of India, 2003.

11 Government of India, Ministry of Health and Family Welfare. IMNCI training module for physicians. Government of India, 2003.

12 Government of India, Ministry of Health and Family Welfare. National program implementation plan RCH phase II-program document. Government of India, 2005.

13 World Health Organization. Essential newborn care: report of a technical working group, Trieste, 25-29 April, 1994. WHO, 1996.

14 World Health Organization. Pregnancy, childbirth, postpartum and newborn care. 2nd ed. WHO, 2006.

15 Government of India, Ministry of Health and Family Welfare. Integrated Management of Neonatal and Childhood IIIness: supervisor module for follow up visit. Government of India, 2005.

16 Carlo WA, Goudar SS, Jehan I, Chomba E, Tshefu A, Garces A, et al. Newborn-care training and perinatal mortality in developing countries. N Engl J Med 2010;362:614-23.

17 World Health Organization. A standard verbal autopsy method for investigating causes of deaths in infants and children. WHO, 1999.

18 World Health Organization. World health report 2005: make every mother and child count. WHO, 2005.

19 Lawn JE, Cousens S, Zupan J. 4 million neonatal deaths. When? Where? Why? Lancet 2005;365:891-900

20 Baqui AH, El-Arifeen S, Darmstadt GL, Ahmed S, Williams EK, Seraji HR, et al. Effect of community-based newborn-care intervention package implemented through two service-delivery strategies in Sylhet district, Bangladesh: a cluster-randomised controlled trial. Lancet 2008;371:1936-44.

21 Baqui A, Williams EK, Rosecrans AM, Agrawal PK, Darmstadt GL, Kumar V, et al. Impact of an integrated nutrition and health programme on neonatal mortality in rural northern India. Bull World Health Organ 2008;86:796-804.

22 Kumar V, Mohanty S, Kumar A, Misra RP, Santosham M, Awasthi S, et al. Effect of community-based behavior change management on neonatal mortality in Shivgarh, Uttar Pradesh, India: a cluster-randomised controlled trial. Lancet 2008;372:1151-62.

23 Bang AT, Bang RA, Reddy HM. Home-based neonatal care: summary and applications of the field trial in rural Gadchiroli, India (1993 to 2003). J Perinatol 2005;25:S108-22.

24 Bhutta ZA, Memon ZA, Soofi S, Salat MS, Cousens S, Martines J. Implementing community-based perinatal care: results from a pilot study in rural Pakistan. Bull World Health Organ 2008:86:452-9.

25 Arifeen SE, Hoque DM, Akter T, Rahman M, Hoque ME, Begum K, et al. Effect of the Integrated Management of Childhood IIIness strategy on childhood mortality and nutrition in a rural area in Bangladesh: a cluster randomised trial. Lancet 2009;374:393-403.

26 Schellenberg JRMA, Adam T, Mshinda H, Masanja H, Kabadi G, Mukasa O, et al. Effectiveness and costs of facility-based Integrated Management of Childhood Illness (IMCI) in Tanzania. Lancet 2004:364:1583-94

27 Bhutta ZA, Soofi S, Cousens S, Mohammed S, Memon ZA, Ali I, et al. Improvement of perinatal and newborn care in rural Pakistan through community-based strategies: a cluster randomised effectiveness trial. Lancet 2011;377:403-12.

28 Baqui AH, Ahmed S, El Arifeen S, Darmstadt GL, Rosecrans AM, Mannan I, et al. Effect of timing of first postnatal care home visit on neonatal mortality in Bangladesh: an observational cohort study. BMJ 2009;339:b282.

Accepted: 30 January 2012

\section{Cite this as: BMJ 2012;344:e1634}

This is an open-access article distributed under the terms of the Creative Commons Attribution Non-commercial License, which permits use, distribution, and reproduction in any medium, provided the original work is properly cited, the use is non commercial and is otherwise in compliance with the license. See: http://creativecommons.org/licenses/by$\mathrm{nc} / 2.0 /$ and http://creativecommons.org/licenses/by-nc/2.0/legalcode. 


\section{What is already known on this topic}

Evaluation of Integrated Management of Childhood IIIness in Tanzania showed a 13\% reduction in childhood mortality beyond the first week of life, whereas evaluation in Bangladesh showed no significant effect

Previous evaluations of community based newborn care interventions showed a $15 \%$ to $61 \%$ reduction in neonatal mortality Most of these evaluations were in relatively small populations, and none included interventions beyond the neonatal period

\section{What this study adds}

Evaluation of Integrated Management of Neonatal and Childhood IIIness, a programme with increased focus on newborn and infant care, showed a reduction in infant mortality

In the subgroup of babies born at home, neonatal mortality was also reduced

Integrating neonatal and child health interventions at community and health facility level is feasible on a large scale for implementation by a district health system

\section{Tables}

\section{Table 1 | Comparison of Intervention-related activities in the intervention and control clusters}

Intervention clusters

Intervention components (put in place January to December 2007)

(1) Improving skills to promote newborn care practices:

Training of community health workers (Anganwadi workers) to conduct postnatal 8 day IMNCI training for basic health workers $\quad$ No home visits

Training of community health workers (accredited social health activists) for women's Training in content and method of conducting
group meetings
group meetings meetings

(2) Improving case management skills:

\begin{tabular}{lll}
\hline Training of community health workers (accredited social health activists) & 8 day IMNCI training for basic health workers & No \\
\hline Training of nurses (auxiliary nurse midwives) & 8 day IMNCl training for basic health workers & No \\
\hline Training of physicians in government health system & 11 day IMNCl training course for physicians & No \\
\hline Orientation of private healthcare providers & Orientation in IMNCl: 6 hours \\
\hline Orientation of traditional birth attendants & Orientation in newborn care: 4 hours & No
\end{tabular}

(3) Strengthening health system to implement IMNCI:

Supervision of community health workers (Anganwadi workers, accredited social Temporary contractual hiring to fill vacant positions, No health activists) and nurses

IMNCI training, effective supervision training

Task based incentives for community health workers (Anganwadi workers, accredited Incentives for community health workers for home No social health activists) for IMNCI activities

Ensuring supply of drugs to community health workers visits, women's group meetings, sick child contacts

\section{Tasks performed by health workers (January 2008 to March 2010)}

Community health workers (Anganwadi workers):

Routine activities—-preschool education, supplementary nutrition, growth monitoring, Yes Establishing drug depots in villages basic medicines

\begin{tabular}{|c|c|c|}
\hline IMNCI activities-home visits after birth for newborn care & Yes & No \\
\hline \multicolumn{3}{|l|}{ Community health workers (accredited social health activists): } \\
\hline $\begin{array}{l}\text { Routine activities-promote hospital deliveries, optimal feeding practices, } \\
\text { contraception, immunisation, treat using essential drugs }\end{array}$ & Yes & Yes \\
\hline $\begin{array}{l}\mathrm{IMNCl} \text { activities-assess, classify, and treat children according to IMNCl, conduct } \\
\text { women's group meetings }\end{array}$ & Yes & No \\
\hline \multicolumn{3}{|l|}{ Nurses (auxiliary nurse midwives): } \\
\hline $\begin{array}{l}\text { Routine activities-immunisation, family planning, first level treatment of children, } \\
\text { participation in village level committee, promotion of institutional deliveries, conduction } \\
\text { of deliveries }\end{array}$ & Yes & Yes \\
\hline $\mathrm{IMNCI}$ activities-assess, classify, and treat children according to $\mathrm{IMNCI}$ & Yes & No \\
\hline \multicolumn{3}{|l|}{ Physicians: } \\
\hline Routine activities-treat sick children and adults & Yes & Yes \\
\hline IMNCI activities-assess, classify, and treat children according to IMNCI & Yes & No \\
\hline
\end{tabular}

IMNCI=Integrated Management of Neonatal and Childhood IIIness. 


\begin{tabular}{lcc}
\hline Table 2| Cluster level and individual level characteristics of intervention and control areas & Intervention & Control \\
\hline Cluster level characteristics from baseline survey (2006) & (9 clusters, 12 028 women) & (9 clusters, 12 585 women) \\
\hline Mean (SD) home births (\%) & $71.9(8.9)$ & $65.9(13.4)$ \\
\hline Mean (SD) illiterate mothers (\%) & $50.1(9.0)$ & $51.5(13.9)$ \\
\hline Median (interquartile range) population per cluster, & $38295(30140-65332)$ & $40539(38250-49869)$ \\
\hline Mean (SD) distance between cluster primary health centre and nearest point on highway (km) & $15.3(11.7)$ & $7.0(5.2)$ \\
\hline Mean (SD) neonatal mortality rate & $32.6(8.1)$ & $32.4(9.1)$ \\
\hline Mean (SD) infant mortality rate & $44.9(14.7)$ & $43.9(10.7)$ \\
\hline Characteristics of families of recruited births (2008-10) & (n=29 667) & (n=30 813) \\
\hline No (\%) illiterate mothers & $11220(37.8)$ & $12846(41.7)$ \\
\hline No (\%) schedule caste or tribe & $7680(25.9)$ & $7188(23.3)$ \\
\hline Median (interquartile range) No of family members & $7(5-9)$ & $7(5-9)$ \\
\hline No (\%) mothers working outside home & $1151(3.9)$ & $979(3.2)$ \\
\hline Median (interquartile range) annual income (rupees) & $60000(36000-100000)$ & $50000(36000-80000)$ \\
\hline No (\%) toilet inside house & $11179(37.7)$ & $14165(46.0)$ \\
\hline No (\%) family below poverty line card & $5449(18.4)$ & $3254(10.6)$ \\
\hline No (\%) possess mobile phone & $21785(73.4)$ & $23199(75.3)$ \\
\hline
\end{tabular}




\section{Table 3| Effect of intervention on mortality outcomes in intervention and control clusters}

\begin{tabular}{|c|c|c|c|}
\hline All live births* & Intervention ( 9 clusters; $n=29667^{\star}$ ) & Control ( 9 clusters; $n=30813^{\star}$ ) & Hazard ratio $(95 \% \mathrm{Cl}) \dagger$ \\
\hline Infant deaths (1-365 days) & 1925 & 2136 & $0.85(0.77$ to 0.94$)$ \\
\hline Neonatal deaths (1-28 days) & 1244 & 1326 & $0.91(0.80$ to 1.03$)$ \\
\hline $\begin{array}{l}\text { Neonatal deaths beyond first } 24 \text { hours after } \\
\text { birth ( } 2-28 \text { days) }\end{array}$ & 635 & 709 & $0.86(0.79$ to 0.95$) \ddagger$ \\
\hline $\begin{array}{l}\text { Perinatal deaths (stillbirths and 1-7 day } \\
\text { deaths)§ }\end{array}$ & 1630 & 1850 & $0.89(0.78$ to 1.00$)$ \\
\hline Post-neonatal deaths (29-365 days) & 681 & 809 & $0.76(0.67$ to 0.85$)$ \\
\hline
\end{tabular}

*Live births to women identified during pregnancy whose vital status at day 29 was known.

†Cox proportional hazard model adjusted for cluster design (shared frailty option, random effects model) and potential confounders (toilet inside house, illiterate mother, schedule caste or tribe, possession of mobile phone, family with below poverty line card, distance from primary health centre to nearest point on highway, percentage of home births in cluster).

$\ddagger$ Adjusted for cluster design with robust standard errors rather than shared frailty option (as model failed to yield estimates) and potential confounders (as above). $\S$ Total number in intervention and control clusters included live births (29 667 and 30 813) and stillbirths (663 and 836 ). 


\begin{tabular}{|c|c|c|c|c|c|}
\hline \multirow[b]{2}{*}{ All live births } & \multicolumn{2}{|c|}{ Home births* } & \multicolumn{2}{|c|}{ Facility births $†$} & \multirow[b]{2}{*}{$\begin{array}{l}\text { P value for test } \\
\text { of interaction }\end{array}$} \\
\hline & $\begin{array}{l}\text { Intervention/control } \\
(n=18536 / 15827)\end{array}$ & Hazard ratio $(95 \% \mathrm{Cl}) \neq$ & $\begin{array}{l}\text { Intervention/control } \\
(n=11131 / 14986)\end{array}$ & Hazard ratio $(95 \% \mathrm{Cl}) \ddagger$ & \\
\hline Infant deaths (1-365 days) & $1146 / 1143$ & 0.77 (0.69 to 0.87$)$ & $779 / 993$ & $0.98(0.87$ to 1.10$)$ & $<0.001$ \\
\hline $\begin{array}{l}\text { Neonatal deaths (1-28 } \\
\text { days) }\end{array}$ & $668 / 643$ & 0.80 (0.68 to 0.93$)$ & $576 / 683$ & $1.06(0.91$ to 1.23$)$ & 0.001 \\
\hline $\begin{array}{l}\text { Neonatal deaths beyond } \\
\text { first } 24 \text { hours ( } 2-28 \text { days) }\end{array}$ & $356 / 366$ & $0.76(0.65$ to 0.90$) \S$ & $279 / 343$ & $1.01(0.90$ to 1.14$) \S$ & 0.012 \\
\hline $\begin{array}{l}\text { Perinatal deaths (stillbirths } \\
\text { and } 1-7 \text { day deaths) }\end{array}$ & $799 / 787$ & 0.80 (0.69 to 0.92$)$ & $831 / 1063$ & 0.99 (0.87 to 1.13$)$ & 0.002 \\
\hline $\begin{array}{l}\text { Post-neonatal deaths } \\
\text { (29-365 days) }\end{array}$ & $478 / 500$ & $0.73(0.63$ to 0.84$) \S$ & 203/309 & $0.81(0.69$ to 0.96$) \S$ & 0.325 \\
\hline \multicolumn{6}{|c|}{$\begin{array}{l}\text { *Live births born at home to women identified during pregnancy whose vital status at day } 29 \text { was known. } \\
\text { †Live births born at health facilities to women identified during pregnancy whose vital status at day } 29 \text { was known. } \\
\text { ¥ Cox proportional hazard model adjusted for cluster design (shared frailty option, random effects model) and potential confounders (toilet inside house, illiterate } \\
\text { mother, schedule caste or tribe, possession of mobile phone, family with below poverty line card, distance from primary health centre to nearest point on highway, } \\
\text { percentage of home births in cluster). } \\
\S \text { Adjusted for cluster design with robust standard errors rather than shared frailty option (as model failed to yield estimates) and potential confounders (as above). } \\
\text { १Total number in intervention and control clusters included live births and stillbirths. }\end{array}$} \\
\hline
\end{tabular}


Table 5| Newborn care practices reported by mothers of enrolled infants four weeks after birth in intervention and control clusters. Values are numbers (percentages) unless stated otherwise

\begin{tabular}{|c|c|c|c|}
\hline Practices & Intervention clusters $(n=6204)$ & Control clusters $(n=6163)$ & Odds ratio $(95 \% \mathrm{Cl})^{\star}$ \\
\hline Breast feeding started within 1 hour & $2527(40.7)$ & $689(11.2)$ & 5.21 (4.33 to 6.28$)$ \\
\hline Pre-lacteal feeds not given & $4977(80.2)$ & 2006 (32.6) & 8.24 (5.68 to 11.95$)$ \\
\hline Exclusively breast fed at 4 weeks & $4811(77.6)$ & $2300(37.3)$ & $6.32(5.29$ to 7.55$)$ \\
\hline Skin-to-skin contact any time on day of birth & $108(1.7)$ & $2(0.0)$ & $175.94(14.69$ to 2107.67$)$ \\
\hline Infant clothed appropriately on first day of life $†$ & $6048(97.5)$ & $6036(97.9)$ & $0.76(0.46$ to 1.24$)$ \\
\hline Infant bathed $\geq 24$ hours after birth & $5243(84.5)$ & $2848(46.2)$ & 6.35 (4.65 to 8.68$)$ \\
\hline Nothing or gentian violet paint applied on cord & $5219(84.1)$ & $2436(39.5)$ & $8.20(6.43$ to 10.45$)$ \\
\hline
\end{tabular}

*Logistic regression adjusted for cluster design and potential confounders (toilet inside house, illiterate mother, schedule caste or tribe, possession of mobile phone, family with below poverty line card, distance from primary health centre to nearest point on highway, percentage of home births in cluster)

tWore at least three layers in winter (November to February) and at least two in other months. 
Table 6| Newborn care practices reported by mothers of enrolled infants four weeks after birth in intervention and control clusters by place of birth. Values are percentages unless stated otherwise

\begin{tabular}{|c|c|c|c|c|c|}
\hline \multirow[b]{2}{*}{ Practices } & \multicolumn{2}{|c|}{ Home births* } & \multicolumn{2}{|c|}{ Facility births $\dagger$} & \multirow[b]{2}{*}{$P$ value } \\
\hline & $\begin{array}{c}\text { Intervention/control } \\
(n=3979 / 3197)\end{array}$ & Odds ratio $(95 \% \mathrm{CI}) \ddagger$ & $\begin{array}{c}\text { Intervention/control } \\
(n=2225 / 2966)\end{array}$ & Odds ratio $(95 \% \mathrm{CI}) \ddagger$ & \\
\hline $\begin{array}{l}\text { Breast feeding started within } \\
1 \text { hour }\end{array}$ & $49.0 / 8.9$ & 9.61 (7.25 to 12.75$)$ & $25.9 / 13.7$ & 2.30 (1.75 to 3.01$)$ & $<0.001$ \\
\hline Pre-lacteal feeds not given & $86.9 / 25.2$ & $19.87(14.19$ to 27.81$)$ & $68.1 / 40.4$ & 3.15 (2.21 to 4.51$)$ & $<0.001$ \\
\hline $\begin{array}{l}\text { Exclusively breast fed at } 4 \\
\text { weeks }\end{array}$ & $78.65 / 33.75$ & 7.52 (6.14 to 9.22$)$ & $75.7 / 41.2$ & $4.98(4.14$ to 6.00$)$ & $<0.001$ \\
\hline $\begin{array}{l}\text { Skin-to-skin contact any time } \\
\text { on day of birth }\end{array}$ & $1.85 / 0.0$ & 136.70 (8.89 to 2100.64$)$ & $1.7 / 0.0$ & $\begin{array}{c}208.26(10.32 \text { to } \\
4204.46)\end{array}$ & 0.783 \\
\hline $\begin{array}{l}\text { Infant clothed appropriately } \\
\text { on first day of life§ }\end{array}$ & $98.9 / 99.2$ & 0.81 (0.42 to 1.57 ) & $94.8 / 96.6$ & 0.70 (0.38 to 1.30$)$ & 0.679 \\
\hline $\begin{array}{l}\text { Infant bathed } \geq 24 \text { hours after } \\
\text { birth }\end{array}$ & $86.9 / 33.8$ & 12.86 (9.19 to 17.99$)$ & $80.3 / 59.6$ & $2.59(1.80$ to 3.74$)$ & $<0.001$ \\
\hline $\begin{array}{l}\text { Nothing or gentian violet } \\
\text { paint applied on cord }\end{array}$ & $87.7 / 35.3$ & $13.50(10.20$ to 17.87$)$ & $77.7 / 44.1$ & 4.50 (3.01 to 6.71$)$ & $<0.001$ \\
\hline
\end{tabular}

*Live births born at home to women identified during pregnancy.

†Live births born at health facilities to women identified during pregnancy.

¥Using logistic regression adjusted for cluster design and potential confounders (toilet inside house, illiterate mother, schedule caste or tribe, possession of mobile phone, family with below poverty line card, distance from primary health centre to nearest point on highway, percentage of home births in cluster).

$\S$ Wore at least three layers in winter (November to February) and at least two in other months. 


\section{Figure}

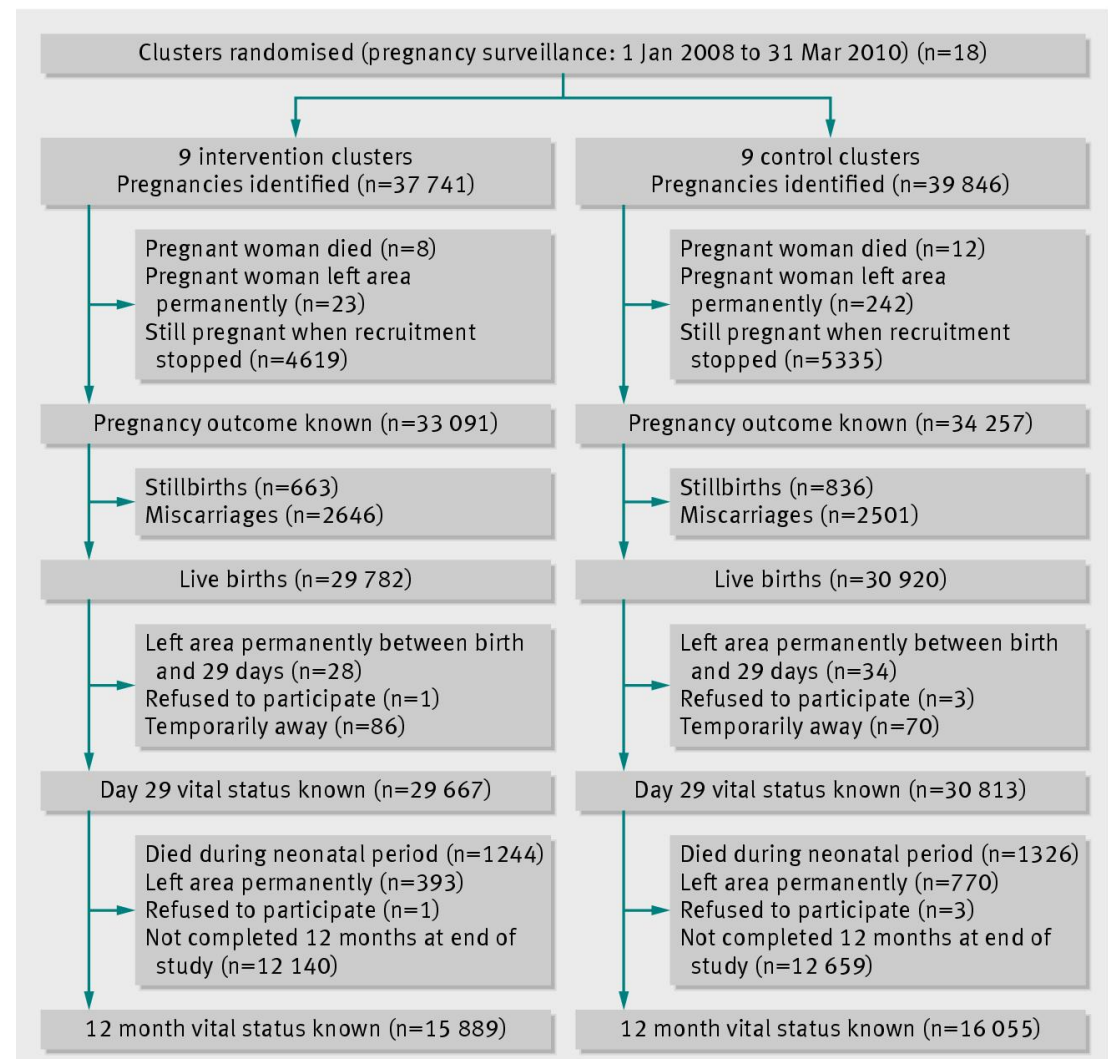

Trial profile. All recruited live births whose vital status was known at 29 days of age were included in analysis 